\title{
Las relaciones laborales vistas a través de la teoría de las opciones estratégicas de los actores
}

\author{
López Pino, Carmen Marina* \\ *Investigación Social Contemporánea, Madrid. E-mail: carmen982000@yahoo.com
}

\section{Resumen}

El presente artículo desentraña el marco analítico de la teoría de las “Opciones Estratégicas de los Actores", propuesta teórica del equipo del M.I.T. (Massachussets Institute of Tecnology) para la explicación y comprensión de las relaciones laborales. Para lo cual aborda primero el enfoque de Dunlop, enfoque del que parte este grupo, y segundo, los conceptos básicos de este marco analítico como son: estrategia, instituciones y entorno. Finalmente, se destaca algunas de sus falencias, y se concluye que, no obstante los vacíos encontrados en las investigaciones del equipo del M.I.T., el marco analítico propuesto por este grupo es un instrumento adecuado, tanto teórico como metodológico, para abordar las relaciones laborales, y debería ser considerado en más investigaciones para contribuir con ello a la formulación de una teoría de las relaciones laborales más sólida y fundamentada.

Palabras clave: Relaciones laborales, teoría de las Opciones Estratégicas de los Actores, sistema de Dunlop, estrategia.

\section{Labor Relations Seen Through the Theory of Strategic Actor Options}

\begin{abstract}
This article explains the analytical framework of the theory of "Strategic Actor Options" proposed by the MIT (Massachusetts Institute of Technology) team in order to explain and comprehend labor relations. The first focus approached by this group is that of Dunlop. The basic concepts of this analytical framework are: strategy, institutions, and environment. Finally some of the fallacies are pointed out, and the conclusion is that even though certain holes are found in the research produced by the MIT team, the analytical framework proposed by this group is an adequate instrument, both theoretically and methodologically, with which to study labor relations, and should be taken into consideration in other studies in order to contribute to the formulation of a more solid and well founded theory of labor relations.
\end{abstract}


Key words: Labor relations, "Strategic Actor Options" theory, Dunlop system, strategy.

Recibido: 03-05-05. Aceptado: 03-07-01

\section{I ntroducción}

El nuevo contexto de internacionalización de los mercados y de innovaciones técnicas y organizativas ha contribuido a transformar las relaciones laborales en los diversos países del mundo. En las dos últimas décadas abundan los estudios orientados a desentrañar en qué consisten estos cambios y cómo han afectado a los diversos actores empresariales y a las sociedades. Los estudiosos europeos de los países desarrollados, dada la particularidad de sus sociedades, centraron su atención en las instituciones y relaciones sociales que contribuyeron a configurar un "sistema nacional de relaciones laborales" de tal magnitud y fuerza que traspasaba la empresa, configurando un orden social. Estudiosos como los del Equipo del M.I.T. (Massachussets Institute of Technology), centrados en el estudio de los Estados Unidos de América, por su parte, mostraron mayor interés en las estrategias de los actores empresariales y en especial las de la empresa $\underline{\underline{1}}$. De esta forma, la discusión teórica y metodológica se centró en estas dos grandes líneas como lo explicitan Locke, Kochan y Piore (1995: 161): “Dos explicaciones opuestas acerca del grado de transformación registrado en las relaciones de trabajo. La primera se inspira en el concepto de "opciones estratégicas" adoptado por el equipo de investigadores del M.I.T., mientras que la segunda, apoyada por muchos de los investigadores europeos que participaron en el proyecto, hace hincapié en la importancia de la influencia restrictiva ejercida por las estructuras establecidas (los mecanismos institucionales, incluidos los órganos y normas laborales), que limitan la libertad de acción individual de las empresas y de los demás actores en el campo de las relaciones de trabajo. Según esta hipótesis, la orientación que caracteriza al M.I.T. exagera la importancia de la empresa como unidad de análisis, y por esa razón descuida los factores que en países con sistemas de relaciones de trabajo más centralizados contribuyen a moldear desde afuera las prácticas de empleo en los centros de trabajo. En consecuencia, los partidarios del segundo enfoque consideran que para explicar los cambios acaecidos en los sistemas más centralizados conviene investigar si se está produciendo o no una transformación sistemática de los mecanismos institucionales pertinentes y los efectos que estos tiene en las empresas.

Con miras a esclarecer estas dos posiciones, en 1995, el Equipo del M.I.T. adelantó una investigación de orden comparativo que denominó Employment relations in a changing world Economy (1995). Buscaba, entre otras, volver a poner sobre el tapete la teoría de las relaciones laborales, que a su entender, no había vuelto a ser revisada de manera 
sistemática desde la propuesta planteada por Dunlop a finales de la década del cincuenta del siglo pasado.

Entre los hallazgos de dicha investigación se cuentan: 1) progresiva descentralización hacia las empresas; esto significa que en todos los países estudiados, la empresa adquiere cada vez mayor relevancia como centro de decisión y de orientación estratégica en materia de recursos humanos y de relaciones de trabajo. Si en el pasado los sindicatos fueron los que promovieron las concesiones de mejores salarios y prestaciones, mientras que los empleadores mantenían una posición defensiva o intentaban ponerse al recaudo de su acción, ahora han sido los empleadores los principales promotores de los cambios. 2) Mayor flexibilidad; la descentralización coincidió con la búsqueda de métodos más flexibles de organización del trabajo y de asignación de mano de obra. 3) Valoración de las cualificaciones profesionales y ampliación de la polarización entre los trabajadores. 4) Diferenciación creciente de la mano de obra en un marco de condiciones y oportunidades diversas que acrecientan la polarización de la fuerza de trabajo. 5) Disminución del número de trabajadores sindicalizados. Y finalmente, concluyen que en los países estudiados se observa el resurgimiento de desigualdades, sea en torno a los ingresos o a las oportunidades de empleo. Esto no sólo amenaza polarizar a estas sociedades entre los que "tienen" y los que " no tienen", sino que también mina los principios de solidaridad de los movimientos obreros tradicionalmente organizados (Locke, et al, 1995a: 163-164 y Locke y Kochan, 1995b: 361-364 y 371).

Aunque sigue reconociendo el papel fundamental de las estrategias de los actores, al considerar los factores históricos nacionales el M.I.T. acepta la existencia de determinantes institucionales que operan con más fuerza en unos países que en otros. Es así como proponen establecer un puente entre las instituciones y las estrategias y llaman la atención sobre la necesidad de adelantar estudios históricos comparativos a nivel internacional, sin olvidar o marginar la esfera micro "sí se quiere mejorar los modelos teóricos y asumir un papel más activo en el fomento de nuevas políticas" (Locke, et al, 1995: 182).

El peso que el Equipo del M.I.T. le confiere a las opciones estratégicas de los actores responde a una opción teórica y metodológica, pero quizás también a una política. Sus investigaciones suelen llamar la atención sobre el poder material e ideológico que tiene hoy el modelo neoliberal sobre las economías de mercado y los principios que rigen la reestructuración económica, concluyen, en consecuencia, que no hay una sola salida (la del mercado) sino múltiples caminos, por lo cual los actores deben establecer estrategias viables y propositivas que impidan que la sociedad sea destruida por el mercado. 
“Las variaciones que revelaron los estudios realizados, tanto en las prácticas aplicadas como en sus resultados, demuestran que no puede haber una sola respuesta o solución a los problemas que plantea la intensificación de la competencia mercantil. Por otra parte, esas variaciones no corresponden a variaciones puramente aleatorias respecto de situaciones regidas por las fuerzas del mercado, sino todo lo contrario: las formas que adoptan las relaciones de empleo son el resultado previsible y sistemático de la acción de los mecanismos institucionales que filtran presiones externas y las estrategias seguidas por los principales actores. Las pautas observadas en los países con una sólida tradición de relaciones centralizadas tienden a seguir rumbos negociados y progresivos con el objetivo de lograr resultados equilibrados que conformen a distintos grupos sociales y económicos... En cambio, en los Estados Unidos y en el Reino Unido, las modificaciones y reformas han tendido a lograrse por vía unilateral, porque los sindicatos, las instituciones que tradicionalmente los apoyan y sus aliados políticos se mantuvieron a la defensiva... Habrá que renovar las funciones de los sindicatos o idear nuevas formas de representar los intereses de los asalariados en los lugares de trabajo, en las decisiones de las empresas y en los órganos que formulan las políticas industriales y económicas" (Locke, et al, 1995: 181, cursiva nuestra).

En ese marco de discusiones y cambios en las relaciones laborales en el mundo se aborda el presente artículo. Pero el interés fundamental del mismo es esclarecer la propuesta analítica desarrollada por el M.I.T. e inspirada en el concepto de "Opciones Estratégicas". A continuación se hace una breve presentación del enfoque de sistemas de Dunlop que el equipo del M.I.T. busca superar. Seguidamente se exponen los principales conceptos y premisas del enfoque de las Opciones Estratégicas de los Actores.

\section{El enfoque de Sistemas de Dunlop}

Las relaciones laborales se configuran como un campo de estudio distinto al económico y al político como consecuencia de la Gran Depresión y la Segunda Guerra Mundial. En sus comienzos fue una preocupación de la política pública, se enfocó en la organización de los trabajadores en sindicatos y en la manera como los trabajadores organizados actuaban para estructurar la economía y, a través de ella, la sociedad en que vivían. Las relaciones laborales intentaban encausar y controlar ese proceso mediante la política pública, es decir, entender cómo podría ser institucionalizado (Locke, et al 1995: i). Esta disciplina empieza a consolidarse en la década del cincuenta y sesenta con las obras pioneras de John Dunlop, Industrial Relations Sistems (1958) y el trabajo conjunto de este autor con Kerr, Harbison y Myers en la obra el "Industrialismo y el hombre industrial" (1960). Su principal interés fue sentar las bases teóricas de la disciplina de las relaciones laborales o 
industriales $\underline{\underline{2}}$. En su momento representó una ruptura con el tradicional empirismo que caracterizaba los estudios sobre las relaciones industriales, muchos de ellos centrados en las negociaciones colectivas. En 1963 Kerr, Dunlop, Harbison y Myers planteaban: “En lugar de concentrarnos tan intensamente en la protesta, nos volvimos hacia el fenómeno realmente universal que afecta a los trabajadores: la inevitable estructuración de los administradores y los administrados en el transcurso de la industrialización. Por doquiera se desarrolla una compleja trama reglamentaria que enlaza el trabajador con el proceso industrial, con su trabajo, con su comunidad, con los moldes de conducta. ¿Quién elabora las normas? ¿Cuál es la naturaleza de ellas? El problema laboral por excelencia en el desarrollo económico no es el cómo manejar la protesta, sino el de la estructuración de la fuerza de trabajo" (Kerr, et al 1963:18).

Estos investigadores se interesaron, y esa fue su contribución, en reclamar para las relaciones industriales el carácter de disciplina con un objetivo propio. En su libro Sistema de relaciones industriales Dunlop sostiene: “Explicar los motivos por los que se establecen determinadas reglas en determinados sistemas de relaciones industriales y cómo y por qué cambian en respuesta a cambios que afectan al sistema (Dunlop, 1978: 22)... La idea de un sistema de relaciones industriales implica una unidad, una interdependencia y un equilibrio interno que puede ser restaurado si el sistema se tambalea, con tal que no haya cambios fundamentales en los actores, contextos o ideologías. Los sistemas de relaciones industriales muestran una gran tenacidad y persistencia. La unidad esencial de un sistema de relaciones industriales hace surgir dudas acerca de la transferencia de reglas, prácticas o arreglos de un sistema a otro" (Dunlop, 1978: 46).

La propuesta de Dunlop tiene gran influencia de la teoría de sistemas parsoniana, pero a diferencia de éste subdividió el sistema social global en tres subsistemas: el sistema político, el sistema económico y el sistema de relaciones industriales, distanciándose con ello de la idea original de Parsons y Smelser, quienes sólo aceptaron la existencia de cuatro subsistemas: el político, el económico, el integrativo (o cultural) y el de la gestión del conflicto y de mantenimiento del patrón (o sistema legal) (Espina, 1999:375). Esta opción, permite a Dunlop situar todas las disputas industriales, y la forma en que se manejan, dentro de un "sistema de relaciones industriales" cuya dimensión, a su vez, puede variar de una empresa a un sector o al conjunto del país. Pero, aunque varíe su dimensión, un sistema de relaciones industriales posee ciertas propiedades y estructuras comunes y responde a influencias específicas.

Para Kerr, et al (1963) todo sistema de relaciones industriales, independientemente de su forma, cumple por lo menos tres funciones fundamentales en las sociedades 
industrializadas: 1) Define los deberes y responsabilidades correspondientes a los trabajadores, los gerentes y el Estado; define y establece las relaciones de poder y autoridad. 2) Controla y mantiene dentro de límites tolerables las reacciones de los trabajadores industriales y los directores frente a las dislocaciones, frustraciones e incertidumbres inherentes al proceso de industrialización. 3) Establece el complejo de normas, prácticas y reglamentos, tanto sustantivos como de procedimiento, necesario para el lugar y la comunidad de trabajo. Estas tres son funciones interdependientes pero no necesariamente se realizan de la misma manera, ni según las mismas disposiciones, en los diferentes sistemas de relaciones industriales (Kerr et al, 1963: 245). Para estos autores la institucionalización de las relaciones laborales, es decir, su cristalización en un sistema tripartito, es inherente a todo proceso de industrialización (Kerr, et al, 1971: 590). En resumen, para Kerr et al, el problema central de las relaciones laborales en todo el mundo no es la confrontación entre el capital y la mano de obra, sino la estructuración misma de la fuerza de trabajo: la forma como se contrata, desarrolla y mantiene. Esta es la tarea cotidiana de las relaciones laborales en todas partes (Kerr, et al, 1971: 591 y Kerr, et al, 1963: 175).

\section{Límites del Modelo de Dunlop}

A pesar de las críticas hechas a este enfoque, una de las virtudes que se le reconoce es su voluntad de abarcar el conjunto de relaciones industriales y explicitar una base teórica. Si miramos hacia atrás, por ejemplo, F.W. Taylor no quería formular un modelo teórico, hablaba en términos de método y rechazaba la noción de sistema, de hecho, fue uno de los primeros en plantear la posibilidad de un análisis científico de la organización industrial. Por su parte, Elton Mayo cuestionaba el pensamiento individualizador y tecnicista de Taylor e insistía en el trabajo como actividad de grupo; le concedía gran importancia a las motivaciones psicológicas y sociales de los trabajadores. No obstante ambos autores partían de los mismos supuestos: 1) Encontrar los factores que influyen en la producción y cómo se la puede aumentar. 2) Conciben a la empresa como una unidad cerrada de la que se excluyen los elementos exteriores. 3) La organización es vista como una suma de individuos que pueden tener intereses individuales y diversos pero nunca antagónicos y que colaboran "lógicamente" por un engrandecimiento de la empresa (Estivill, 1978: 16).

Dunlop se distancia de esta noción eficientista y de la noción de la empresa como una unidad cerrada. Según Estivill (1978) uno de los méritos del sistema de relaciones industriales de Dunlop es que, siendo fiel a los supuestos ideológicos de los anteriores pensadores, los desborda. En primer lugar porque al afirmar que el elemento sustantivo 
de las relaciones sociales en el trabajo es su cuerpo de reglas de conducta rebasa la insistencia tecnológica y psicológica propias de Taylor y de Mayo. Amplía la perspectiva y se sitúa en una vertiente más sociológica y jurídica. En segundo lugar, porque al tener en cuenta los imperativos técnicos, de mercado y presupuestario y la distribución del poder rompe las fronteras del territorio exclusivo de la empresa lo cual se refuerza con su propuesta sobre la composición de los actores que intervienen en las relaciones industriales (Estado, trabajadores y empresarios). En este sentido Dunlop da un paso adelante al incorporar a su modelo las diversas organizaciones que pueden agrupar a los actores como instancias colectivas diferenciadas, esto es, el sindicalismo obrero y los organismos patronales (Estivill, 1978:10).

Para Watson (1994) este enfoque, que se enmarca dentro de la teoría estructural funcionalista parsoniana, supera la metáfora clásica de la dirección que concibe la organización como una máquina racionalmente concebida y construida para cumplir de forma eficiente los objetivos de sus diseñadores. Dunlop sustituye esta concepción por la metáfora de la organización como un organismo vivo y en constante adaptación para supervivir en un entorno potencialmente amenazador. En primer lugar, reconoce que las estructuras oficiales establecidas por los fundadores son más bien pautas de relaciones que sufren un proceso constante de adaptación para permitir que la empresa se mantenga. En segundo lugar, resalta las estrechas interrelaciones entre las diferentes partes o "subsistemas" de la organización y la tendencia a que los cambios en una parte del sistema influyan en las otras (Watson, 1994).

No obstante, el valor del pensamiento de sistemas radica en el protagonismo que confiere a las estructuras y pautas de la vida social corrigiendo así los enfoques excesivamente individualistas que suelen llamarse "psicologismo". Sin embargo, el enfoque de Dunlop lleva a reificar las normas, las estructuras terminan sustituyendo a los actores como foco de atención; éste no parece reconocer que el mundo social es creación de los individuos y grupos que interactúan asignando significados y haciendo interpretaciones de sus situaciones.

La postura teórica estructural-funcionalista que subyace a este enfoque lleva a sus autores a asumir una constante preocupación por la estabilidad del sistema de relaciones industriales. En esta propuesta la ideología y las normas tienen un papel relevante como reguladoras y garantes del orden. En este punto se centran las críticas hechas al enfoque a este enfoque (Lucena, 1998). Hyman cuestiona el papel que cumplen las normas como reguladoras y estabilizadoras del sistema y, en general, la importancia que adquiere el problema del "orden": a Dunlop le interesa más saber cómo se estabilizan las pautas de 
relación social, que averiguar los efectos que tienen sobre ellas los desafíos a la estructura social imperante (Hyman, 1981: 21).

Bajo las premisas de la estabilidad del sistema y de la unidad de intereses, es muy difícil imaginar cómo podría aplicarse el modelo de Dunlop a los momentos de ruptura histórica (fase revolucionaria, guerras), a las sociedades en vía de desarrollo o a las que están atravesadas por graves contradicciones antagónicas. Las dificultades para aplicar este modelo teórico a las situaciones más distantes del mundo norteamericano representan los límites más claros de este trabajo. Dunlop supone que empresarios y trabajadores disfrutan de la misma situación de partida $y$, aunque reconoce que tienen intereses distintos, cree que la presión que ejercen puede inclinar la balanza a favor de uno u otro. El Estado interviene desde afuera. Para Estivill (1978) las deficiencias de la posición de Dunlop en lo que respecta al poder están en la falacia de la igualdad de origen y de la neutralidad de la dimensión política. Esta teoría considera que toda sociedad industrializada tiene un sistema de relaciones laborales integrado por actores que gozan de poder de negociación (empresarios y trabajadores) bajo la regulación del Estado. Pero esta situación es poco frecuente en muchos países en vía de desarrollo donde la legitimación de los actores sindicales o la regulación o intermediación del Estado en las relaciones laborales no han sido paralelas al proceso de industrialización.

En 1971 Kerr, Dunlop, Harbison y Myers reconsideraron su postura y plantearon que los países en "fase de desarrollarse" presentan una serie de particularidades que impiden la aplicación completa de su modelo; reconocieron, además, que en estas sociedades la falta de consenso es más generalizada. Entre las especificidades citadas están: 1) el estancamiento rural, 2) el crecimiento desordenado de subclases urbanas, 3) la enseñanza no está orientada hacia las necesidades del desarrollo; 4) fallas en la organización burocrática y corrupción y 5) altas tasas de crecimiento demográfico y de la fuerza de trabajo (Kerr, et al, 1971: 594).

La influencia del pensamiento de sistemas en las relaciones industriales ha sido menos duradera en Europa, especialmente en aquellos países que adoptaron una visión del conflicto industrial. Los investigadores del M.I.T. que proponen el enfoque de las Opciones Estratégicas de los Actores parten de la teoría de Dunlop pero buscan superarla. De ahí que presente continuidades y discontinuidades como se observará enseguida.

\section{Perspectiva de las Opciones Estratégicas de los Actores en las relaciones laborales}

\subsection{Distanciamiento de los postulados del enfoque de Dunlop}


La Escuela de las Opciones Estratégicas de los Actores recoge varias de las críticas hechas a Dunlop, Locke, Piore y Kochan (1995) sostienen que el enfoque de las relaciones laborales era en exceso funcionalista, tecnológicamente determinista y etnocéntrico. Era funcionalista porque explicaba las prácticas en función de su contribución a la eficacia económica y a la estabilidad social; determinista porque entendía la evolución de las relaciones laborales como resultado de un singular dinamismo tecnológico; etnocéntrico porque al ver a Estados Unidos como el líder tecnológico presentaba sus instituciones y prácticas como los modelos para ser emulados por otras naciones. Las relaciones laborales en otros países, entonces, se concibieron como derivados o desviaciones del modelo norteamericano (Locke, et al, 1995: xvii).

Pero también reconocen que Dunlop ofreció el marco teórico utilizado por los investigadores de los años sesenta y setenta para elaborar modelos que explicaran las diferencias en las relaciones laborales entre empresas y sindicatos. De hecho, como afirman Locke, et al (1995), el modelo de Dunlop funcionaba bastante bien siempre y cuando el entorno y las prácticas de las partes implicadas se mantuvieran estables. No obstante, era cada vez más claro que el marco de los sistemas, con su insistencia en la estabilidad y en el consenso de los protagonistas en sus respectivos papeles, encontraba grandes dificultades para explicar los aspectos dinámicos de las relaciones laborales. A su entender, si se deseaba interpretar las transformaciones de las relaciones laborales, era justamente estos rasgos dinámicos lo que había que comprender (Kochan, Katz y MacKersie, 1993: 28).

El enfoque de las Opciones Estratégicas de los Actores se distancia del de Sistemas de Dunlop en dos aspectos fundamentales. En primer lugar, en la idea del consenso. La concepción original de Dunlop admite la posibilidad de que no haya una ideología compartida entre empresarios y trabajadores, sin embargo, esto fue pasado por alto en las investigaciones posteriores. La gran mayoría de los estudios, incluyendo el de Dunlop para el caso estadounidense, se apoya en el supuesto implícito de que en la época del New Deal hubo una ideología común en Estados Unidos. Pero, como demuestran Kochan, Katz y MacKersie (1993), es precisamente la ausencia de una ideología común lo que permite explicar, en parte, los cambios ocurridos en las relaciones laborales norteamericanas.

El modelo de relaciones laborales del New Deal se convirtió en la forma dominante de negociación colectiva después de la Segunda Guerra Mundial y hasta los años setenta. Marcó la pauta en la gestión de los recursos humanos, incluso en los lugares donde los sindicatos no habían adquirido todavía derechos de representación. Varios fueron los 
rasgos de nivel estratégico del sistema de relaciones laborales del New Deal. Primero, la previsión de que los empresarios aceptarían pragmáticamente la negociación colectiva. Segundo, el principio de que a cambio de la aceptación del papel de los sindicatos en la determinación de los salarios, horarios y condiciones de trabajo, los empresarios mantendrían la iniciativa en las decisiones empresariales y en las acciones a nivel de fábrica. Tercero, la formación de un sindicalismo interesado por el "control de las condiciones laborales" que permitiría el establecimiento de convenios y procedimientos, muy estructurados, para resolver judicialmente las diferencias surgidas durante la vigencia de los contratos. De acuerdo con este sistema, los derechos y obligaciones de los trabajadores estaban vinculados a puestos de trabajo rigurosamente desarrollados y con una configuración muy detallada (Kochan, et al, 1993).

No obstante, para Kochan et al (1993), el consenso entre empresarios, trabajadores y gobierno no siempre supuso el abandono de una ideología poco favorable a la presencia de los sindicatos en los ámbitos empresariales. Este consenso fue el resultado de una estrategia pragmática de los empresarios que fue bien recibida por los trabajadores y que contó con el respaldo de las entidades gubernamentales. Este modelo fue replanteado a finales de la década del sesenta y comienzos del setenta. Las presiones del entorno, concentradas en la mayor competencia exigida por la internalización creciente de la actividad económica y la desreglamentación de la industria americana, llevaron a una creciente incertidumbre del ambiente comercial a la cual se sumaron las fluctuaciones de los precios del petróleo, de los tipos de cambio y de inflación y las transformaciones del mercado laboral que terminaron contribuyendo a modificar las relaciones laborales en los Estados Unidos. Las nuevas estrategias empresariales combinaron medidas contradictorias de reducción de costos de mano de obra y valorización de las calificaciones y enfatizaron en calidad del producto, innovación, flexibilidad productiva y políticas de motivación orientadas a establecer relaciones de cooperación y de confianza entre los trabajadores y la dirección empresarial. En este marco la demanda pública de los empresarios americanos de un entorno laboral "sin sindicato" se considera social y políticamente aceptable. Ellos afirman que: “indudablemente, el supuesto de que existe un conflicto legítimo de interés en la relación de empleo no es compartido por la mayoría de empresarios americanos, aunque encuentre expresión en las políticas públicas" (Kochan et al, 1993:31).

Lo anterior sugiere que una estrategia de "consenso" no necesariamente se sustenta en principios consensuales que suponen el reconocimiento del otro como actor válido para la negociación. A largo plazo una estrategia de consenso genera acuerdos frágiles entre las partes. 
El segundo aspecto en el cual la teoría de las Opciones Estratégicas se distancia, de manera explícita, de la teoría tradicional es sobre quién, o quiénes, promueven o sufren los cambios. Hasta la década de los ochenta, un importante número de estudios centraba los cambios de las relaciones laborales en la negociación colectiva cuyo principal objetivo era lograr unas relaciones laborales pacíficas y estables. Puesto que los cambios solían atribuirse a los gestores de la negociación colectiva o de las políticas de recursos humanos los estudios se enfocaban en la negociación colectiva; se consideraba que los empresarios se limitaban a reaccionar ante las reivindicaciones, presiones e iniciativas sindicales.

Según Kochan et al (1993), en los últimos años hubo numerosos indicios de que esta relación causal se había invertido. En Estados Unidos las innovaciones en las prácticas de gestión de los recursos humanos iniciadas en las empresas no sindicalizadas se extendieron cada vez más a las sindicalizadas. La alta dirección, no el profesional tradicional de gestión de personal, promovía cambios que no siempre eran una respuesta de choque a la presión sindical. Este hallazgo obligó a abordar los niveles superiores de la estructura empresarial para considerar una serie de decisiones estratégicas que, aunque repercutían en los intereses básicos de los trabajadores en relación con la seguridad en el empleo, eran tomadas muy por encima del alcance de los trabajadores, de sus representantes sindicales o del proceso de negociación colectiva tradicional.

\subsection{Tesis de la teoría de las Opciones Estratégicas de los Actores}

La teoría de las Opciones Estratégicas de los Actores se ha ido construyendo de manera colectiva a través de diversas investigaciones, de ahí que hasta el momento ésta tenga un carácter básicamente analítico pues sus autores en sus escritos no desarrollan con amplitud los conceptos en los que se apoyan. La incorporación de conceptos determinantes en la configuración de las relaciones laborales ha sido el resultado, en parte, de estudios comparativos de investigadores del M.I.T y de otros países del mundo que, además de las estrategias de los actores, han enfatizado en el papel de las instituciones como reguladoras y constitutivas de las relaciones laborales.

En la investigación sobre "La transformación de las relaciones laborales en los Estados Unidos" (Kochan et al, 1993), por ejemplo, los autores fueron más allá de la descripción e interpretación de los acontecimientos coyunturales y presentaron una perspectiva más estratégica sobre las relaciones laborales en los Estados Unidos; demostraron que las estructuras del futuro no están inalterablemente predeterminadas por fuerzas económicas o tecnológicas, o de alguna otra índole, existentes en el entorno americano. La argumentación básica es que las prácticas y resultados de las relaciones laborales se 
configuran en las interacciones de las fuerzas ambientales, así como en las decisiones estratégicas y la escala de valores de los empresarios, dirigentes sindicales, trabajadores y autoridades públicas (Kochan, 1993: 25).

El equipo del M.I.T. considera las historias nacionales y locales, en especial las mentalidades de los empresarios construidas históricamente, como elementos fundamentales de su análisis. Desde esta perspectiva las estrategias de los empresarios están permeadas por su opinión sobre las organizaciones sindicales. Los directivos empresariales responden al entorno exterior orientados por este sistema de valores (Kochan, 1993:37).

Su propuesta se afina y enriquece con estudios comparativos. En su investigación sobre Employment relations in a changing world Economy (1995), sugiere que la naturaleza de las prácticas de empleo y las relaciones laborales se deriva de la interacción entre los cambios en las condiciones del entorno empresarial y las estrategias de los empresarios, de los trabajadores y de los actores gubernamentales (Locke, et al, 1995: 373). También resalta la necesidad de realizar una propuesta teórica que, primero, integre acciones institucionales y opciones estratégicas de los actores en un solo armazón predictivo y, segundo, que preste mayor atención a los factores históricos que crean puntos de partida "diferentes" o condiciones de fondo para generar, obstruir o propugnar el cambio (Locke y Kochan, 1995: 379). A similares conclusiones llegan en el estudio After lean production, envolving employment practices in the world auto industry (Kochan, et al, 1997:7).

Nos detendremos en la consideración de los tres determinantes o categorías analíticas: contexto externo, estrategias e instituciones, considerados hilos conductores de la teoría de las Opciones Estratégicas de los Actores. No obstante su importancia en las diversas investigaciones estos conceptos no han sido explicitados teóricamente. Este vacío obliga a hacer una pesquisa más allá de las obras del grupo del M.I.T, tomando en consideración, brevemente, la discusión de la teoría de la acción racional y el institucionalismo y el neoinstitucionalismo.

\subsubsection{Las Opciones Estratégicas}

Kochan, Katz y MacKersie (1993), en su investigación "La transformación de las relaciones laborales en los Estados Unidos", se apoyan en la obra de Alfred Chander, Strategy and Structure (1966), para explicar las relaciones entre estrategia y estructura y entre estructuras de gestión y políticas de relaciones laborales de las empresas. Para el análisis del concepto de estrategia se retoma dicho texto y The visible Hand (1977) del mismo autor. La tesis planteada por Chandler en La mano visible (1988) es: “La empresa 
moderna reemplazó a los mecanismos de mercado en la coordinación de las actividades de la economía y en la asignación de sus recursos. En muchos sectores, la mano visible de la dirección sustituyó a lo que Adam Smith denominó la mano invisible de las fuerzas del mercado. El mercado continuó siendo el generador de la demanda de bienes y servicios, pero la empresa asumió las funciones de coordinar el flujo de mercancías a través de los procesos de producción y de distribución existentes y de asignar el capital y la mano de obra para la producción y la distribución futuras. A medida en que la empresa moderna adquirió las funciones realizadas hasta entonces por el mercado, se convirtió en la institución más poderosa de la economía norteamericana, y sus directivos, en el grupo más influyente de los responsables de la toma de decisiones económicas. Por consiguiente, la aparición de la empresa moderna de Estados Unidos trajo consigo el capitalismo gerencial" (Chandler, 1988: 15).

El capitalismo gerencial apareció cuando la jerarquía directiva asalariada pudo controlar y coordinar las actividades de un determinado número de unidades operativas de modo más eficiente que los mecanismos de mercado. Siguió creciendo bajo una jerarquía constituida por directivos cada vez más profesionales. La mano visible de la gerencia directiva sustituyó a la mano invisible de las fuerzas del mercado allí donde y en el momento en que la nueva tecnología y los mercados en expansión permitieron la circulación, sin precedentes históricos, de un elevado volumen de mercancías a una gran velocidad, a través de los procesos de producción y de distribución.

La empresa se convierte en una institución sólida, capaz de transformarse internamente y de modificar, incluso, su entorno. Ya no está totalmente sujeta a los vaivenes del mercado sino que puede, a través de las estrategias de sus actores, moldearlo, e incluso redefinirlo. Más que la empresa en abstracto, Chandler se refiere a la gran empresa, especialmente a la empresa oligopólica, la cual, desde el siglo pasado, posee un basto poder en los Estados Unidos y en el mundo. En el capitalismo gerencial la empresa se convierte en una institución consolidada, cuya salud presente y crecimiento futuro dependen de los individuos que guían sus actividades. Sobre los altos ejecutivos y sus mandos medios recae la responsabilidad fundamental de la fortuna de las empresas porque son ellos quienes asumen e implementan decisiones estratégicas orientadas a garantizar la permanencia y rentabilidad de la empresa (Chadler, 1987:8).

Para Chandler, incluso para el grupo del M.I.T, el principal actor que propulsa el cambio empresarial es la alta gerencia, ella debe formular, promover y coordinar la materialización de las políticas y estrategias empresariales. Aunque el M.I.T no desestima el papel que pueden, y deben, cumplir las organizaciones sindicales y el Estado les resta 
importancia porque, históricamente, en los Estados Unidos estos dos actores han tenido un papel menos preponderante en el desarrollo empresarial y en la economía en su conjunto (Chandler, 1988: 672). Las decisiones estratégicas buscan la continuidad y rentabilidad de la compañía a largo plazo; aunque pueden ser formuladas por niveles inferiores a la alta dirección su implementación requiere de recursos materiales o de poder que sólo ella puede proporcionar.

La estrategia puede definirse, no sólo como la determinación de las metas básicas y objetivos a largo plazo de una empresa, sino como la adopción de cursos de acción y la asignación de recursos necesarios para llevar a cabo estas metas (Chandler, 1987:13). La tesis de Chandler es que la asunción de estrategias supone cambios en la estructura de la empresa; una estructura compleja es el resultado del encadenamiento de varias estrategias básicas. Para que una estrategia de diversificación, de fusión o de integración vertical pueda cristalizar de forma eficiente y eficaz, por ejemplo, hay que transformar la estructura interna de la empresa. Un corolario importante de esta tesis es que el crecimiento sin ajuste estructural sólo puede llevar a la ineficacia económica.

Aunque el equipo de M.I.T no reflexiona explícitamente sobre el concepto de estrategia, del análisis de sus investigaciones se deduce e infiere una concepción de estrategia y de actor más compleja que la planteada por Chandler. Este autor interpreta la estructura empresarial como funcional y no como la cristalización de relaciones sociales. Sus investigaciones se centran en las estrategias de los empresarios y directivos gerenciales y no consideran las estrategias ni de los trabajadores ni de las organizaciones sindicales. Sin embargo, este enfoque no invalida su aporte fundamental: hacer visible la "mano" de la dirección empresarial en la gestión económica restando fuerza explicativa al mercado. Sin embargo, es necesario clarificar aún más el concepto de estrategia, razón por la cual se abordará brevemente la teoría de la acción racional para, a continuación, entrelazar las acciones estratégicas de los actores con las instituciones.

\subsubsection{La acción racional y el concepto de estrategia}

Al contrario que para la economía neoclásica, para la Escuela de las Opciones Estratégicas el actor no es un actor ahistórico ni atomizado, ni está provisto de una supuesta soberanía absoluta a la hora de elegir personalmente su propio comportamiento; tampoco está "intencionalmente autodeterminado", es decir, no es dueño de sus actos, no decide su destino, no elige su conducta ni selecciona personalmente su comportamiento. Tampoco significa que no esté revestido necesariamente de algún voluntarismo o intencionalismo; además, su comportamiento racional no implica que actúe en función de 
sus preferencias, como supone la teoría microeconómica neoclásica.

Bajo las anteriores premisas, para entender la acción estratégica tendríamos que considerar, entonces, que el actor interactúa con otros, que tiene intereses diversos, contradictorios y cambiantes, que se pregunta siempre por los mejores medios para obtener unos fines dados, que posee una información limitada, que se desenvuelve en un entorno cambiante y poblado de otros agentes racionales, potencialmente capaces de interferir el curso esperado de la acción, es decir, que su decisión depende de lo que decidan los demás.

Esta perspectiva se distancia de la consideración general de estrategia, entendida como “toda selección de cursos alternativos de acción (recursos tácticos) por su virtualidad para producir resultados futuros (objetivos estratégicos) en situaciones de incertidumbre" (Garrido y Gil Calvo, 1993:14). Según Garrido y Gil Calvo, este concepto identifica tres requisitos básicos, aunque insuficientes para entender el concepto de estrategia. Primero, la disposición de un margen de maniobra, o de un abanico más o menos amplio de posibilidades de elección, en tanto que oportunidades alternativas abiertas a la acción; tal puede ser, por ejemplo, su misma omisión, pues ella sola, intencionada o no, es alternativa a la acción estratégica. Segundo, objetivos a largo plazo, definidos de antemano y sea cual fuere el criterio y la coherencia de su definición. Tercero, la existencia de alguna clase de incertidumbre en el entorno, sin la cual no hay acción estratégica sino acto reflejo, hábito adquirido, rutina normativa o determinismo de la acción (Garrido y Calvo, 1993:14).

Pero este concepto de estrategia olvida que el actor (empresario, directivo, trabajador o líder sindical) es un actor que interactúa con el otro y que su comportamiento se explica por los intereses que contrae al ocupar posiciones estructuralmente relacionadas. En términos de Gil Calvo: "Los intereses que determinan los actos ni son propios de los individuos ni tampoco siquiera de las posiciones que éstos ocupan: sino más bien de las relaciones sociales de interdependencia recíproca que se establecen estructuralmente entre unas posiciones y otras" (Gil, 1993: 237).

Esta posición estructural y las relaciones sociales de interdependencia recíproca son claras en el ámbito empresarial. La empresa es una unidad en la que se entretejen relaciones sociales entre actores (empresarios, directivos, mandos medios, trabajadores y dirigentes sindicales), en un marco de relación social de dominación y autoridad que configura relaciones contradictorias entre capital y trabajo, sin excluir momentos de cooperación y de conflicto. Esto lleva al problema de los intereses y de los recursos de 
poder entre los actores. Históricamente pueden existir intereses comunes y contradictorios, e incluso antagónicos, entre los directivos empresariales y las organizaciones sindicales y los trabajadores, pero también entre trabajadores y organizaciones sindicales. Aunque el trabajador se encuentra en igual situación de clase y posee un conjunto de intereses comunes al resto de trabajadores, debido a su condición particular, a su historia personal ligada a su trayectoria laboral y a sus expectativas individuales también tiene sus propios intereses.

Los intereses entre los actores pueden ser comunes pero también contradictorios y cambiantes; no son inherentes a los individuos en tanto individuos, es decir, no les pertenecen por su propia naturaleza de individuos actuantes (Gil, 1993:237). Todo esto permite comprender la variedad, el cambio y el conflicto de los intereses y por tanto la dificultad de llevar a cabo acciones estratégicas que no contemplen los intereses o que no cumplan con las expectativas del otro. Si bien el actor empresarial interactúa con otros, su interacción no suele estar basada en el consenso sino en el conflicto (donde cada actor estratégico trata de alcanzar sus objetivos en contra de la oposición de sus antagonistas) o en el poder (donde algunos actores disponen de la capacidad de obligar a otros, mediante amenazas, incentivos o seducciones, a plegarse a su voluntad) (Gil, 1993: 243). El núcleo esencial del concepto de opciones estratégicas se sustenta, sobre todo, en el margen de variación de los recursos tácticos de los que disponen los actores empresariales y no tanto en los objetivos estratégicos mismos (que pueden no existir en cuanto tales).

Aunque, por definición, el concepto de Opciones Estratégicas supone la existencia de cierta autonomía de los directivos empresariales en la toma de decisiones y un margen de negociación o poder de los trabajadores en relación con sus condiciones de trabajo que les permite actuar ante un contexto interno o socioeconómico global, este margen de maniobra es diferencial para directivos, trabajadores y líderes sindicales y dependerá de los recursos de poder de cada uno. La información es un elemento básico, no sólo para seleccionar los medios más adecuados para la obtención del fin, sino para establecer relaciones de confianza y, en esa medida, reducir el riesgo y la incertidumbre e, incluso, abandonar, en algunas situaciones, acciones estratégicas. La información, recurso de poder, le permite al actor adentrarse en mayores procesos de reflexividad y por tanto de acciones estratégicas. Como afirma Lamo de Espinosa: "Si mi interés es estratégico, la máxima reflexividad emerge cuando yo sé lo que él espera de mí, pero no viceversa y así, generando un plano superior de reflexividad, me burlo de su expectativa utilizando un lenguaje ya estándar, podemos pues, decir que si el juego entre ego y alter es de tipo cooperativo la reflexividad se agota en un primer nivel: ego sabe lo que alter espera de él 
y viceversa. La dinámica cooperativa no exige ni requiere niveles ulteriores de reflexividad. Si, por el contrario, el juego entre ego y alter es competitivo, la dinámica fuerza a cada uno a elevarse por encima del nivel de reflexividad del contrario. En el primer caso la reflexividad se cierra enseguida; en el segundo la reflexividad es potencialmente infinita" (Lamo de Espinosa, 1993: 419).

Si yo sé (o creo saber) lo que el otro espera de mí estoy en condiciones de realizar su expectativa o de frustrarla, puedo ajustarme a ella o puedo -con igual conciencianegarla. Dicho de otro modo: él está en mis manos pues mi acción puede adquirir un carácter estratégico frente a él. Una acción estratégica supone que la decisión del actor depende de lo que decidan los demás; más aún, él orienta su acción por lo que otro espera de él (Lamo de Espinosa, 1993: 422).

No obstante, las consideraciones de Lamo de Espinosa que basa el concepto de estrategia en elementos cognitivos, hay que señalar que los actores, en su cotidianidad, no suelen orientarse estratégicamente, ni siquiera en un ámbito supuestamente "racional" como el de las empresas. Ya desde la década del cincuenta teóricos de la organización, como Hebert Simon, argumentaban que los seres humanos no optimizan sus decisiones organizacionales debido, fundamentalmente, a dos razones: 1) su capacidad cognitiva es limitada por lo que no son capaces de captar y procesar toda la información adecuada al problema que enfrentan. 2) Normalmente las decisiones organizacionales se toman bajo severas restricciones de tiempo y presupuesto lo que hace imposible la optimización (Vergara, 1993: 124).

Por eso el modelo racional de toma de decisiones, que tiene como objetivo la optimización de los recursos organizacionales, es irreal. A partir del concepto de "racionalidad limitada", planteado por Simon, y del estudio del comportamiento organizacional durante el proceso de toma de decisiones surgieron dos ideas fundamentales. La primera es reconocer que la capacidad de atención de las organizaciones es un recurso escaso. Las instancias decisorias organizacionales sólo pueden enfocar su atención selectivamente y por períodos más bien cortos (March y Simon, 1958, citado por Vergara, 1993). En consecuencia, la organización desarrolla estrategias de simplificación que le permiten manejar los cientos de decisiones que tiene que tomar cotidianamente. La rutinización es la estrategia de simplificación de la vida organizacional. El grueso de miembros de la organización se comporta conforme a rutinas cuyo objetivo es reducir los procesos de toma de decisiones; los miembros de la organización son entrenados para obedecer este conjunto de reglas y fundamentar sus decisiones en él. Saber que los individuos no intentan optimizar sino que se contentan con 
actuar por rutina modifica de manera importante el análisis de la toma de decisiones de individuos y organizaciones.

En la versión clásica el modelo racional de toma de decisiones se componía de los siguientes pasos: 1) El sujeto examina todos los posibles cursos de acción. 2) El sujeto construye todos los futuros escenarios a los que llevaría cada alternativa examinada. 3) El sujeto compara estos escenarios futuros y selecciona aquel que maximice su función de utilidad. Es importante señalar que este modelo de racionalidad supone, además de información completa, que el sujeto conoce sus preferencias y que éstas son estables, es decir, no serán alteradas en el futuro (Vergara, 1997: 12).

El modelo de "racionalidad limitada" deja de lado el propósito de encontrar la alternativa óptima por lo cual no tiene necesidad de examinar exhaustivamente todo el abanico de alternativas posibles. Los pasos del modelo son los siguientes: 1) El sujeto decisor establece cuál es el nivel mínimo de resultados favorables que está dispuesto a aceptar. 2) El sujeto examina un número relativamente pequeño de cursos de acción. 3) El sujeto construye los escenarios futuros a que lo llevan las alternativas estudiadas. 4) Cuando el sujeto encuentra un escenario futuro en el que sus necesidades son "satisfechas" detiene la búsqueda y selecciona esta alternativa. Este modelo de "racionalidad limitada" no requiere información completa pero sí asume que las preferencias son estables y que el sujeto decisor las conoce. Vergara acepta que el modelo de "racionalidad limitada" no es un paradigma diferente del modelo racional clásico pero introduce nuevos elementos en el estudio de la toma de decisiones. El más importante de ellos es reconocer que al tomar una decisión las organizaciones operan con recursos escasos, el tiempo, la información y la capacidad para procesarla, y con limitados recursos de poder (Vergara, 1997: 13).

Por su parte March y Olsen (1997) plantean que los intereses, y por tanto los objetivos de los actores, no son estables, ni consistentes, ni precisos, ni exógenos al proceso de decisión. Cambian a menudo, son ambiguos y en algunas ocasiones los agentes pueden tener objetivos contradictorios. Además, los objetivos no son exógenos al proceso de tomar una decisión, a veces los agentes no tienen claro lo que quieren y durante el proceso mismo aclaran y establecen sus objetivos. En lugar de sujetos bien informados y claros con respecto a sus objetivos, hay sujetos mal informados, inseguros con respecto a sus objetivos e incluso vacilantes entre objetivos contradictorios.

Circunscribiéndonos al ámbito de la empresa, los objetivos de los directivos empresariales están ligados a los intereses adquiridos al ocupar una posición estructuralmente relacionada dentro de la empresa (no se descartan intereses de orden 
personal para los cuales el éxito de la empresa sea un medio). Por un lado, el objetivo último de la dirección empresarial es la rentabilidad, los medios para lograrlo pueden estar vinculados a una variedad de objetivos, incluso, inconsistentes entre ellos. Por ejemplo, la rentabilidad puede depender de objetivos orientados a mejoras en la productividad, en la calidad y en el servicio de post-venta, a la diversificación de productos, a la reducción de costos laborales y al logro de un ambiente laboral confiable y predecible, objetivos éstos que, a su vez, suponen la elección de medios que pueden ser inconsistentes con el conjunto de objetivos. Por esta razón el actor debe establecer una escala de prioridades que le permita desestimar un objetivo a favor de otro. Por otro lado, los intereses de los trabajadores también son cambiantes y diversos y los medios que empleen para lograrlos dependen, en parte, de la coyuntura y de sus recursos de poder, tanto individual como colectivo.

Con las anteriores salvedades y ante la ausencia de una suficiente profundización del concepto de estrategia por parte del Equipo del M.I.T., siendo su propuesta teórica básicamente de carácter analítica, es sugestivo considerar también el concepto de estrategia de Crozier y Friedeberg por su complejidad y riqueza. Estos autores plantean que para entender el concepto de estrategia son necesarias las siguientes consideraciones: el actor rara vez tiene objetivos claros y menos todavía proyectos coherentes, estos son más o menos explícitos y más o menos contradictorios. El suyo es un comportamiento que siempre tiene un sentido; en lugar de ser racional con arreglo a ciertos objetivos lo es, por una parte, en relación con las oportunidades y a través de éstas con el contexto que las defina y, por otra, en relación con el comportamiento de los otros actores, con el partido que toman y con el juego que se establece entre ellos.

“En resumen, un comportamiento que siempre presenta dos aspectos: uno ofensivo, que es aprovechar las oportunidades con miras a mejorar su situación, y otro defensivo que consiste en mantener y ampliar su margen de libertad y por ende su capacidad de actuar. Esta oposición se encuentra sin que necesariamente haya equivalencia en una perspectiva temporal (ganancia a corto plazo contra inversión); lo importante es la dualidad y no el significado de los términos... En el caso límite, no existe, pues, un comportamiento irracional; esa es la utilidad que tiene el concepto de estrategia " (Crozier y Friedeberg, 1990: 47).

Como las opciones están inscritas en estructuras institucionales e históricas concretas, la gama de opciones viables de la que disponen los actores en un momento determinado se ve parcialmente limitada por los resultados de anteriores decisiones y por la distribución actual del poder dentro de la empresa y entre ella y los posibles sindicatos, organismos 
gubernamentales $u$ otras organizaciones externas con las que se relacionan (Kochan et al, 1993:34-35).

Para resumir, en momentos determinados, el actor empresarial puede asumir acciones estratégicas, es consciente de estar en un medio inestable en el que reinan el riesgo y la incertidumbre, con la tragedia de saberse poseedor de más y más información para definir opciones estratégicas pero igualmente consciente de su insuficiencia respecto al dinamismo de los cambios, a la variabilidad de las estrategias de los otros y a los limitados recursos de poder que posee. Actos que no siempre son resultado de las intenciones o acciones del actor, pues sus acciones pueden desencadenar en actos no deseados, ni siquiera pensados, así disponga de información para prever y responsabilizarse de sus acciones.

Si bien es un actor cada vez más reflexivo, en términos de Lamo de Espinosa, sus acciones no siempre se orientan por elementos racionales sino que son el resultado de su interpretación de la realidad, de sus intereses, de sus valores, de sus hábitos y emociones. En fin, es un actor complejo y obligado al aprendizaje permanente. No obstante, parafraseando a Aguiar, las estrategias de la dirección empresarial no abandonan su carácter normativo, esto es, se preguntan siempre por los mejores medios para obtener unos fines dados dejando a un lado la racionalidad de los fines mismos (Aguiar, 1993: 350).

Para el Equipo del M.I.T. como las opciones estratégicas de los actores son filtradas por la red de instituciones existente a todo nivel -tanto del entorno como en el centro de trabajo-, es necesario establecer un puente entre el actor y las instituciones.

\subsubsection{Un puente entre las Opciones Estratégicas de los Actores y las Instituciones}

Típicamente, los modelos racionales prestan poca atención a los contextos en los que se desenvuelve el actor; por el contrario, el nuevo institucionalismo argumenta que los contextos institucionales - políticos, sociales, económicos- dentro de los que actúan los individuos influyen de manera importante sobre su comportamiento. Según esta corriente, las organizaciones desarrollan características institucionales que diferencian a unas de otras y que se constituyen en el factor de análisis más importante si se quiere entender el comportamiento de los actores organizacionales. El objetivo del nuevo institucionalismo es, en consecuencia, analizar los procesos por los cuales las instituciones desarrollan sus características e influyen en el comportamiento de sus miembros (Vergara, 1997: 17). 
Vergara (1997) señala que el nuevo institucionalismo es una teoría que explica convincentemente la estabilidad en los procesos sociales. Esta explicación descansa en dos ideas: 1) Las instituciones sólo cambian en forma incremental, es decir, poco a poco y en plazos de tiempo relativamente largos. 2) Las normas y reglas institucionales influyen de manera determinante en el comportamiento individual. Cuando los individuos actúan en contextos institucionales observan un comportamiento relativamente estable, aún en circunstancias en las que un análisis racionalista sugeriría cambiar de conducta. Sin embargo, es un hecho que, aunque sea sólo incrementalmente, las instituciones cambian y que la conducta de los actores puede variar dentro del mismo marco institucional. La Escuela de las Opciones Estratégicas se detiene en esta última consideración y plantea que uno de los determinantes del cambio de las relaciones laborales son las estrategias de los actores.

Mientras algunos sociólogos pertenecientes al nuevo institucionalismo rechazan todo principio de racionalidad en el comportamiento de los individuos, el equipo del M.I.T. acepta cierto nivel de racionalidad. Los individuos tienen que tomar decisiones para lo cual, aunque no intenten optimizar sus acciones, realizan ciertos cálculos que podrían asimilarse a ejercicios de "racionalidad limitada". Incluso, como señalan March y Olsen, los individuos obedecen las normas institucionales, entre otras razones, porque hacerlo es una estrategia eficaz para reducir la incertidumbre y simplificar la toma de decisiones (March y Olsen, 1997: 35).

Pero en la medida que las instituciones filtran las opciones estratégicas de los actores se podría establecer un puente entre acciones estratégicas e instituciones. Las diversas formas o configuraciones de las relaciones laborales son el resultado de un entramado de relaciones, históricamente configuradas, cristalizadas en reglas constitutivas y regulativas, $\underline{3}$ solidificadas, a su vez, en instituciones. En este sentido, las relaciones laborales son el resultado de acciones de los actores en un marco de instituciones configuradas, interpretadas y reinterpretadas por los actores, consciente 0 inconscientemente. Retomando a Giddens, López Novo plantea: “Las instituciones confieren capacidades genéricas a los actores, las cuales les permiten actuar en contextos específicos, pero también les asignan recursos formales de poder y autoridad constituidos por las instituciones - en otras palabras, todas la instituciones tienen una dimensión de organización formal que provee a los individuos con recursos para la acción, pero lo hace de manera diferenciada" (López Novo, 1993: 320).

Este enfoque se distancia de la mirada estructural de las instituciones porque rescata el voluntarismo de los actores sociales y su capacidad para construir el mundo institucional 
en el que operan. Además, considera, en parte, la sugerente propuesta de Berger y Luckman (1998): “La lógica de las instituciones (...) no radica en la institución y funcionalidad externa, sino en el modo como son tratadas en la reflexión sobre ellas"포. Esta afirmación no debe llevar a desconocer la objetividad de las instituciones como hechos sociales que se imponen al individuo y le posibilitan su integración social a la vez que le constriñen desde el exterior.

También se aparta de la visión instrumentalista de las instituciones que las considera meros instrumentos de acción en manos de los actores, que éstos pueden forjar, ajustar o, simplemente, abandonar a voluntad. Las instituciones están dotadas de una autonomía que se impone a los actores. Aunque el cambio voluntarista de las instituciones por medio de la acción colectiva no es imposible, si es más improbable cuanto mayores sean sus costos. Las instituciones pueden perdurar aun cuando los resultados colectivos que producen sean subóptimos (Krasner, 1988: 73, citado por López Novo). Una institución que evoluciona por décadas de cambio incremental puede estar lejos del ideal. Pero, mientras tanto, serán más los tipos de comportamientos, tanto de patrones como de obreros, que se habrán adaptado a las instituciones.

Las instituciones son cruciales en una situación de interdependencia y tiene consecuencias para las opciones estratégicas. Primero, para seleccionar un curso de acción que aumente al máximo sus propios intereses los actores deben tener en la cuenta la acción de otros. Segundo, al tomar sus decisiones los actores deben ser consciente de que sus opciones afectan y pueden cambiar las opciones de otros. En otras palabras: en las situaciones de interdependencia los actores deben construir sus expectativas considerando al otro u otros y lo que ellos podrían hacer. Aquí es donde las instituciones sociales entran en la historia: ellas proporcionan tanto la información como las sanciones. Estos dos mecanismos ayudan a los actores a formular expectativas y a aumentar la previsibilidad mediante la consistencia.

Para Ruysseveldt et al, el comportamiento institucional aumenta la previsibilidad (predictibilidad), esto es, permite anticiparnos al comportamiento de otros y permite a otros anticiparse al nuestro. Por consiguiente, las instituciones permiten a cualquier actor inventar las más complejas estrategias y seguir las metas más ambiciosas (porque los márgenes de incertidumbre sobre los comportamientos de los otros se reducen). Pero hay un precio que pagar. North (1990: 4) define las instituciones como "constreñimientos inventados humanamente que forman la interacción humana". Las Instituciones trabajan como un filtro selectivo en la toma de decisiones, en sentidos cognitivo y normativo: dentro del juego de todas las posibles opciones de comportamiento o conducta las 
instituciones seleccionan un juego más limitado que es apropiado en una situación dada. Lo que se gana en concertación y previsibilidad puede perderse en alegría y originalidad. Friedrich Hayek expresa bastante bien esta dialéctica: las instituciones abrevian la lista de circunstancias que hay que tener en cuenta en casos particulares, escoge clases de verdades o de hechos para determinar el tipo general de acción que se debe tomar. Al mismo tiempo, esto significa que los actores desatienden sistemáticamente ciertos hechos (Hayek, 1964: 11, citado por Ruysseveldt, et al, 1996: 6).

La rigidez institucional ("la artritis institucional") está en el centro de los debates sobre la renovación del Estado del Bienestar, los acuerdos colectivos y la representación sindical. Un logro importante de las instituciones es haber disminuido la presión directa de los mercados en los ciclos económicos, en el infortunio de los sueldos, en los ingresos y en las oportunidades de los obreros y sus familias. Las políticas sociales y laborales fueron institucionalmente protegidas de las presiones al tener que demostrar su contribución al desarrollo económico. Según Ruysseveld et al, las relaciones industriales poco institucionalizadas son más susceptibles a las presiones y, por consiguiente, más volátiles en el curso debido porque dependen del estado de la economía o de quién está en el poder (Ruysseveldt et al, 1996:6).

La 'flexibilidad' se volvió el problema importante de las relaciones laborales en los años ochenta. La flexibilización de los mercados de trabajo y de las pericias o habilidades de los trabajadores y el pago y el tiempo del funcionamiento flexibles se han vuelto temas relevantes en la investigación comparativa. La flexibilidad puede entenderse, simplemente, como un movimiento fuera de los arreglos estandarizados en el pasado. Una interpretación más radical ve en el desafío de la flexibilidad la exigencia de un nuevo orden de prioridades; estaría mostrando que los contratos existentes, normas, leyes o convenciones deben ser revisados para permitir mayor variación, de acuerdo con las prioridades económicas de las empresas, del Estado y del mercado de trabajo. Es una llamada para "el desmantelamiento" de las barreras institucionales que han servido para aislar a las relaciones laborales de las preocupaciones concernientes a los cambios y los rendimientos económicos (Streeck, 1987, citado por Ruysseveldt et al, 1996).

Las instituciones son meso estructuras que ensamblan el nivel "micro" de la acción social individual con el nivel "macro" del sistema social, que no es sino un entramado de instituciones $\underline{\mathbf{5}}$. Retomando a Durkheim: “... el acoplamiento/desacoplamiento de lo micro y lo macro depende del nivel meso, del nivel intermedio de vinculación. Si el nivel meso es fuerte, si hay numerosas y profundas estructuras institucionales de vinculación, la impredecibilidad de la conducta micro no se traduce en una simétrica impredecibilidad del 
orden agregado. Y viceversa, en ausencia de una fuerte institucionalización meso, el orden micro no genera orden macro sino desorden macro..." (citado por Lamo de Espinosa, 1996: 85).

En este sentido la ausencia o frágil presencia de instituciones reguladoras que contemplen los intereses de los trabajadores puede propiciar, no sólo relaciones conflictivas, sino una variedad de formas de relaciones de empleo y ampliación de la asimetría de poder a favor del capital. Para lograr la estabilidad de las relaciones de empleo las partes deben regular y establecer reglas (qué, quién y a qué nivel). Es un proceso permanente de construcción, interpretación y reinterpretación de normas, de reglas, de pautas de conducta a nivel del espectro formal e informal. La iniciativa de los actores lleva a cambiar las relaciones de empleo y a reducir la asimetría de poder, intrínseca a la relación entre capital y trabajo. Los trabajadores no son sólo víctimas, ellos pueden participar desarrollando estrategias que limiten la estrategia empresarial. Aunque, en la medida en que se debilitan las instituciones reguladoras de la relación de empleo (red de interacciones de concertación, de negociación entre capital y trabajo con la mediación, regulación u orientación del Estado) gana espacio el mercado.

En su investigación Employment relations in a changing world Economy, Kochan y Locke concluyen que la búsqueda de flexibilidad laboral puede ser un fenómeno general que emana de presiones internacionales, común a todas las naciones industrializadas avanzadas. Sin embargo, sus investigaciones contribuyen a desafiar los modelos neoliberales de economías de mercado y de reestructuración económica que han dominado el discurso político y la política macroeconómica en los recientes años. Las variaciones en las prácticas del empleo y resultados de las diversas investigaciones comparativas demuestran que no hay una sola y natural respuesta a la creciente competición del mercado. Se observa que ni las variaciones ni las desviaciones absolutamente aleatorias han sido determinadas sólo por el mercado. En cambio, se observa cómo las instituciones filtran las presiones externas y cómo las relaciones laborales se transforman debido a las estrategias de los actores importantes. Los países que tienen una historia institucional de relaciones laborales centralizadas y fuertes tienden a seguir un modelo de ajuste más incremental y negociado, que apunta a lograr resultados que equilibren los intereses de los diversos grupos sociales y económicos (Locke y Kochan, 1995: 365, 382).

Según Kochan et al, ese armazón institucional no surge espontáneamente; debe crearse deliberadamente a través de la ley y su funcionamiento debe ser motivado por diversos actores y dirigido por la política pública. Para que pueda funcionar la actividad económica 
requiere una estructura institucional, la desreglamentación no puede proceder indefinidamente sin la desintegración eventual de la propia economía. Cuando se empiezan a alcanzar esos límites se debe decidir qué partes de las estructuras restantes serán conservadas y/o reformadas. En un contexto de economía internacional esto tendrá que ser hecho con referencia a las instituciones y estructuras de otras naciones, incluso las relaciones del empleo de las instituciones gobernantes. El debate emergente sobre las normas obreras internacionales es, entonces, sintomático del problema básico que este nuevo régimen comercial representa para la política pública y para la investigación (Locke et al, 1995: xvi).

Esta línea de argumentación nos lleva a analizar otro de los conceptos básicos de la Escuela de las Opciones Estratégicas, el contexto.

\subsubsection{El contexto exterior}

Los cambios en el entorno exterior (mercado de trabajo, mercado de la producción, tecnología y políticas gubernamentales) inducen a los empresarios a adelantar o a reajustar sus estrategias de tal forma que gran parte de los cambios sucedidos dentro de las empresas responden, aunque no de manera inmediata, a presiones externas. La importancia relativa del entorno o de las respuestas de las partes puede variar con el tiempo. Por ejemplo, las organizaciones no ajustan constantemente sus estrategias y políticas frente a los cambios ocurridos en el entorno. Muchas veces tienen que acumularse considerables presiones antes de que se produzca una adaptación.

“Esta es una de las razones por las que los sistemas de relaciones laborales conocen con frecuencia largos períodos de estabilidad relativa que se interrumpen sólo de forma periódica como consecuencia de grandes transformaciones" (Kochan, et al, 1993: 36).

Uno de los argumentos reiterados en las diferentes investigaciones del equipo del M.I.T es que las empresas exitosas han adoptado estrategias que concuerdan con los cambios del entorno exterior. Es el caso de EE.UU, pasada la Gran Depresión; su clase empresarial, en conjunto con el Estado y las organizaciones sindicales, adoptó estrategias exitosas que le permitieron captar expansivos mercados domésticos. Ante un entorno con expectativas de expansión creciente y conflictos laborales, los empresarios, a pesar de tener una mentalidad reacia a las organizaciones sindicales, asumieron una estrategia pragmática de institucionalización del conflicto y, con ella, de las organizaciones sindicales. A cambio de la aceptación del papel de los sindicatos en la determinación de los salarios, horarios y condiciones de trabajo, los empresarios mantuvieron la iniciativa en las decisiones empresariales y en las acciones a nivel de fábrica. Esto dio como resultado un crecimiento 
económico estable acompañado de un aumento de las organizaciones sindicales, además de la atenuación y regulación de los conflictos laborales. Pero entre 1960 y 1980 los cambios en los mercados de producción y de trabajo presionaron por la reestructuración empresarial. Al elegir la manera de responder tanto a las nuevas oportunidades comerciales como a la necesidad de reducir costos, las decisiones de los empresarios americanos fueron dominadas por una clara tendencia a actuar al margen de los sindicatos, excepto en los casos en que los altos niveles preexistentes de sindicación impidieron seguir este camino (Kochan, et al, 1993:35).

En la actualidad, el desafío está en adaptar las economías a los mercados globales de una economía mundial. Los empresarios deben asumir estrategias que combinen una orientación hacia la calidad, la reducción de costos y un mercado diversificado aunado a una gran capacidad de innovación (Kochan y Useem, 1992). Para Kochan y Useem, los empresarios estadounidenses han mostrado más disposición a adaptar sus estrategias a los cambios ocurridos en su entorno y a los cambios en las políticas y estrategias de gestión, que las organizaciones sindicales y las gubernamentales. Hasta los años ochenta, la mayor parte de los sindicatos americanos se mantuvo firme en sus tradiciones de negociación colectiva y se resistió a los esfuerzos de ampliar sus actividades para hacer frente a la reivindicación de mayor participación de los trabajadores en el lugar de trabajo y a los cambios en los mercados y tecnologías.

Como la teoría tradicional de las relaciones laborales, los teóricos de las Opciones Estratégicas también consideran a los gestores empresariales, en especial a la alta dirección, como los actores más dinamizadores de los cambios. Pero, a diferencia de la teoría tradicional, los actores no están sólo expuestos al entorno sino que interactúan con y en el entorno y pueden transformarlo. Al reconocer que el despliegue exitoso de las estrategias empresariales requiere llevar a cabo cambios integrales y continuos en las prácticas organizativas y del entorno, los teóricos de las Opciones Estratégicas se distancian de una posición meramente voluntarista. Además, consideran que para lograr la institucionalización de los cambios éstos deben ser ampliamente difundidos a través de las organizaciones en lo cual cumplen un rol importante las políticas económicas, de recursos humanos y de mano de obra promovidas por los gobiernos. También se distancian del estructural-funcionalismo de la teoría de sistemas de Dunlop quien, retomando al Parsons de la década del cincuenta, reconoce capacidades estratégicas en los actores; sin embargo, la sobrevaloración de lo normativo no sólo dificulta explicar el cambio y el conflicto sino que resta capacidad estratégica a los actores que finalmente terminan siendo parte funcional del sistema. 
Como resultado de la investigación Employment relations in a changing world Economy (1995), el equipo del M.I.T propone ampliar las instituciones que conforman ese entorno y determinan o presionan los cambios en las relaciones laborales. Inicialmente considera el mercado de trabajo, el mercado de la producción, la tecnología y las políticas gubernamentales; después de esta investigación resalta la importancia del sistema educativo y de entrenamiento y la regulación del mercado de trabajo por parte de entidades gubernamentales, instituciones determinantes, a su vez, de la configuración de las relaciones laborales en países como Alemania, Francia y Japón. También destaca el papel del Estado como regulador, orientador y gestor de políticas, situación escasamente considerada en sus primeras investigaciones debido al discreto papel jugado por el Estado en los Estados Unidos pero significativo en algunos países europeos y en Japón.

El equipo del M.I.T afirma que con la globalización el entorno asume un papel más determinante en la transformación de las relaciones laborales, incluso el sistema de relaciones laborales pierde poder de negociación y, por tanto, capacidad para incidir en los cambios. Las políticas neoliberales pretenden convertir el mercado en el regulador determinante de la economía y de las relaciones laborales por lo cual, afirman, en los años recientes las relaciones laborales han estado fuera de moda. Los sindicatos se han convertido en actores pasivos, aparentemente incapaces de determinar los eventos y/o los resultados. El predominio del mercado, asociado a los constreñimientos impuestos a las políticas gubernamentales las cuales fueron culpabilizadas del desempleo, la inflación y el estancamiento económico, ha restado capacidad a los clásicos actores de las relaciones laborales (empresarios, trabajadores y Estado). Las relaciones laborales han sido reducidas a los nichos de las escuelas de negocios; se empiezan a prescribir estrategias empresariales de orden individual distantes de la tradicional política global existente en los países desarrollados, caso los europeos y en menor medida en los Estados Unidos.

\subsubsection{Estructura institucional en tres planos}

Según Kochan, Katz y MacKersie (1993) la labor confiada a la teoría intelectual de las relaciones laborales es identificar las variables fundamentales o fuerzas institucionales que determinan los resultados de la relación entre trabajadores y empresarios. Por eso, en su investigación sobre "La transformación de las relaciones laborales en USA", sugieren abordar las relaciones laborales en tres niveles: 1) Nivel superior de las decisiones estratégicas. 2) Nivel medio o funcional de la negociación colectiva o de formulación de políticas de personal. 3) Nivel inferior, correspondiente al lugar de trabajo, en que se ponen en práctica las políticas que, a su vez, influyen cotidianamente en los representantes sindicales, supervisores y trabajadores. 
El interés de esta propuesta de estructura institucional en tres niveles no es teórico solamente; representa el escenario más basto de interrelación de los profesionales de las relaciones laborales dentro de las organizaciones patronales, sindicales y gubernamentales. En este marco, el nivel medio engloba el ámbito más tradicional de las relaciones laborales ya que se centra en la práctica de la negociación colectiva y de la formulación de políticas de personal, así como en el desarrollo y administración de las políticas públicas fundamentales que regulan las relaciones entre trabajadores y empresarios. Las decisiones adoptadas en el nivel superior, referentes a las políticas y estrategias a largo plazo, por los diversos actores van a depender del grado de institucionalización y poder social de negociación de los actores involucrados. Y por último, las opciones estratégicas relevantes para el nivel inferior son las más directamente asociadas con la organización del trabajo, la estructuración de los derechos del trabajador, la gestión y motivación de los individuos o los grupos de trabajo y la naturaleza del entorno laboral. En este ámbito se incluyen cuestiones como el diseño de puestos y organización del trabajo, las normas laborales, las relaciones entre trabajadores y supervisores y las políticas públicas que regulan los derechos individuales en el centro de trabajo, como leyes sobre la seguridad e higiene o la igualdad de oportunidades de empleo (Kochan \& MacKersie, 1993: 43).

Como todo ello forma parte de la relación dinámica y cotidiana entre trabajadores y empresarios, las actividades que se registran en este último nivel no suelen estar bajo el control directo del proceso de negociación colectiva, las políticas oficiales de personal o las grandes estrategias empresariales. Sin embargo, sí figuran en el contexto de las políticas de los convenios negociados cuya decisión se adopta en niveles superiores del sistema.

Para Kochan \& McKersie (1993), una de las razones que justifica la utilidad de este marco en tres niveles es que aborda en forma específica las aparentes incoherencias y contradicciones internas en las estrategias y prácticas en diferentes niveles de las relaciones laborales dentro de las empresas. El equipo M.I.T. ilustra, para el caso estadounidense cómo las empresas que han promovido activamente la cooperación entre trabajadores y empresarios en sus centros de producción sindicalizados han adoptado, al mismo tiempo, en los niveles superiores, complicadas estrategias destinadas a excluir a los sindicatos de los nuevos centros de trabajo. Cómo se ha llegado a esta situación, cuáles son las condiciones que hacen posible su continuidad y cuáles son sus consecuencias para las relaciones laborales son algunas de las inquietudes que podrían analizarse con esta propuesta analítica.

Los autores resumen las ventajas de su propuesta en los siguientes términos: 1) 
Reconoce las interrelaciones entre las actividades en diferentes niveles del sistema y ayuda a explicar los orígenes de las posibles contradicciones internas o incoherencias entre los tres niveles. 2) Considera los efectos que las diversas decisiones estratégicas tienen sobre los diferentes protagonistas del sistema. 3) Favorece el análisis desempeñado por los trabajadores, los empresarios y el gobierno en sus respectivos ámbitos y actividades (Kochan \& MacKersie, 1993: 44).

\section{Consideraciones finales}

El planteamiento analítico del Equipo del M.I.T. para el estudio de las relaciones laborales, inspirado en el concepto de "opciones estratégicas", desborda el concepto mismo al relevar en sus investigaciones el papel de las fuerzas ambientales y de las instituciones. Si bien, en un primer momento toma como elemento central las estrategias de los actores, en la práctica, dependiendo de la particularidad de la realidad analizada, da una dimensión importante a las instituciones en la medida en que éstas filtran las estrategias de los actores, y al entorno que presiona a elaborar y reelaborar estrategias, en el marco de una relación de interacción mutua.

Sin embargo, a nuestro entender la debilidad fundamental de la teoría de las Opciones Estratégicas de los Actores es la escasa relevancia que otorga tanto al ámbito político como al conflicto y el poder en las relaciones laborales.

Se entiende lo político como el proceso social mediante el cual las personas, o sus agrupaciones, se distribuyen poder, autoridad y recursos de modo que las decisiones alcanzadas poseen fuerza y entran en vigor dentro un ámbito dado (Giner, et al, 1998). El ámbito político es uno de los determinantes de las relaciones laborales pues, por un lado, favorece o no su institucionalización en el nivel de lo macro y de lo micro y, por otro, contribuye o no a legitimar a los actores relevantes (Estado, empresarios, sindicatos y trabajadores) y a construir y consolidar instituciones constitutivas y regulativas de las relaciones laborales como, por ejemplo, la confianza entre los actores.

En países con una industrialización tardía, o en vía de desarrollo, las estructuras institucionales de vinculación de las conductas micro, representadas por el sistema de relaciones laborales, son frágiles y no regulan de manera suficiente las relaciones en el interior de las empresas. Esta debilidad genera una diversidad de formas de relaciones laborales poco favorables al orden social y a la democratización de las condiciones contractuales y laborales de los trabajadores. En los países europeos desarrollados los partidos políticos han contribuido de forma importante a la construcción y consolidación de la regulación de las relaciones y condiciones de trabajo, bien sea en forma directa, a 
través de la articulación de los trabajadores a un partido determinado. En algunos casos, los partidos incorporaron los intereses de los trabajadores al sistema político consolidándolos como grupos fuertes de representación lo cual fue muy favorable para la movilización de recursos y la validación de sus luchas.

Dice Dombois (1997) que para regular de manera general las condiciones laborales no basta que las relaciones industriales institucionalizadas sean reconocidas como legales y legítimas o por lo menos como ineludibles; también deben ser divulgadas y obligatorias en tanto "instituciones básicas" sociales, capaces de imponer estándares mínimos en la regulación de las relaciones laborales en las empresas; tienen que trascender los ámbitos aislados empresariales y alcanzar una generalización y legitimidad en la sociedad. Esto será posible si hay un ámbito político que considere legítimo y propicie la institucionalización de las relaciones laborales. En sociedades de industrialización tardía la existencia de estas condiciones es precaria.

Un Estado débil que no cumple la responsabilidad de regular el conflicto general, función indispensable para garantizar un orden mínimo legal a los ciudadanos, releva el ámbito de lo político, no por su fuerza sino por su carencia de capacidad reguladora, como suele ocurrir en algunos países en vía de desarrollo. Por ejemplo, en algunos países latinoamericanos, la cultura política excluyente y oligárquica, ha dificultado la configuración de un sistema de relaciones laborales y socavado la institucionalización y legitimación de la organización sindical y la lucha de los trabajadores. El caso colombiano muestra que en los estudios de las relaciones laborales es importante considerar, teórica y empíricamente, el ámbito político. De ahí que sería necesario ampliar la gama de actores e incluir tanto los actores e instituciones que siempre ha reconocido la teoría de las relaciones laborales (Estado, gremios empresariales y sindicales y/o trabajadores), como los que están por fuera del sistema político institucionalizado (los partidos y grupos de izquierda -entre los que se cuenta la guerrilla y los paramilitares-) al igual que los partidos tradicionales.

Es probable que el marco analítico propuesto por el Equipo del M.I.T. no resalte el ámbito de lo político porque la mayor parte de sus investigaciones han sido realizadas en países desarrollados, en los que las instituciones de vinculación de acciones micro y macro son fuertes y contribuyen a garantizar el orden y en los que hay amplios y legítimos poderes que sirven de base -en algunos casos- para el establecimiento de relaciones de confianza entre capital y trabajo. Estas condiciones reducen el riesgo y la incertidumbre, favorecen el establecimiento de relaciones de cooperación entre las partes involucradas (empresa, trabajadores y Estado) y, en consecuencia, desestiman las acciones 
estratégicas en momentos determinados.

Las acciones gubernamentales, de los partidos políticos y de los grupos sociales configuran el ámbito de lo político porque ejercen una influencia importante en la institucionalización de los sistemas nacionales de relaciones industriales. La política es el espacio de los fines, es allí donde se construyen colectivamente los proyectos sociales y políticos deseables para una sociedad en un momento histórico determinado. Es, en últimas, el espacio de construcción y validación de las ideologías que en la esfera material o en la del trabajo filtran las estrategias tanto de los empresarios como de los trabajadores; la política y sus instituciones los provee de representaciones mutuas y de alguna manera de comportamientos sociales esperables, elementos de gran importancia para el despliegue de las estrategias.

Teórica y empíricamente, hoy por hoy, este ámbito debería ganar más fuerza en las reflexiones de los estudiosos de las relaciones laborales pues la propuesta neoliberal es liberar progresivamente a la "economía" de todo control político -el significado principal del término "economía" es "el área de lo no político"- (Bauman, 1999: 90). Esto supone despojar a los trabajadores de las protecciones que les brindan las instituciones reguladoras, entre ellas las estatales, que en su momento sirvieron para incorporar la fuerza de trabajo al mercado de trabajo, constituir la clase obrera y regular el proceso de proletarización (Offe, 1990).

La creciente conflictividad política en la que se debaten algunos países contribuye a debilitar la confianza, institución básica para cualquier tipo de relación social, y a destacar lo político. El conflicto disminuye aún más la ya escasa confianza entre las partes respecto a los acuerdos, procedimientos, negociación de los medios e, incluso, a los fines empresariales. En un contexto político atravesado por múltiples intereses y violencias la posibilidad de que la dirección empresarial materialice con éxito estrategias de orden económico y laboral es incierta y de alto riesgo. Lo mismo sucede con los trabajadores cuyas estrategias individuales y colectivas están insertas en un ámbito político y laboral poco favorable a la acción colectiva.

La poca importancia que se otorga al conflicto y a las relaciones de poder entre capital y trabajo es la segunda debilidad de la teoría de las Opciones Estratégicas de los Actores, insuficiencia manifestada en varias de sus investigaciones. El empleo es una relación de poder asimétrica y de intercambio y el conflicto una de sus formas de expresión, por eso debe ser un elemento central en cualquier marco analítico que aborde las relaciones laborales. Ningún hecho es en sí mismo fuente de conflicto, y aunque lo fuera, sus formas 
de expresión son diferentes de acuerdo con el orden empresarial y las opciones estratégicas asumidas individual y colectivamente por los trabajadores. Además, no hay que olvidar el supuesto teórico y metodológico de que los actos son el resultado de las consecuencias queridas o no de las acciones de los actores (Lamo, 1990: 52).

Por último sólo resta señalar que la importancia dada al conflicto no presupone considerar relaciones intrínsecas de solidaridad entre los trabajadores; al contrario, se parte del reconocimiento de una situación diferencial, tanto contextual como personal, que ha generado un proceso de fragmentación expresado en luchas y competencia entre los trabajadores. Las relaciones sociales entre capital y trabajo son complejas e, incluso, impredecibles: control, resistencia y cooperación hacen parte del análisis sociológico que procura articular acción y estructura como una unidad.

No obstante los vacíos encontrados en las investigaciones del equipo del M.I.T., el marco analítico propuesto por este grupo es un instrumento adecuado, tanto teórico como metodológico, para abordar las relaciones laborales, y debería ser considerado en más investigaciones para contribuir con ello a la formulación de una teoría de las relaciones laborales más sólida y fundamentada.

*Este artículo hace parte del capítulo teórico de la tesis doctoral de la autora titulada "Las relaciones laborales en Colombia, vista a través de la teoría de las Opciones Estratégicas de los Actores", presentada en la Universidad Complutense de Madrid.

1. Pertenecen a esta escuela investigadores como Thomas Kochan, Michael Piore, Harriz Katz, Robert MacKersie, Michael Useem, Paul Osterman, Richard Locke, Russell Lansbury y John Paul MacDuffie, entre otros. Varios estudios validan su marco analítico, entre ellos The second industrial Divide-Possibilities for properity (Piore, Michael y Sabel, Charles, 1984), La transformación de las relaciones laborales en los Estados Unidos (Kochan, Thomas, Katz C. Harriz y MacKersie, Robert, 1993), Employment relations in a changing world Economy (Kochan, Thomas, Locke, Richard and Piore Michael (edit), 1995) y After lean production, envolving employment practices in the world auto industry (Kochan, Thomas, Lansbury, Russell D. y MacDuffie, John Paul, edt.1997). Estas investigaciones, además, aplican y refinan la teoría en países industrializados y de industrialización reciente como, por un lado, Estados Unidos, Japón, Alemania, Francia, Inglaterra, Italia, Suecia, Noruega, España, Canadá, Australia, Japón y, por otro, Brasil, Corea y Sur África.

2. En este artículo se hablará indistintamente de relaciones laborales o industriales.

3. Según López Novo "a diferencia de las reglas regulativas, que pueden ser articuladas en máximas de conducta, 
las reglas constitutivas no son reglas externas, sino reglas inherentes a las prácticas sociales de los actores y no son susceptibles de ser articuladas en máximas de conducta. Estas reglas confieren unidad, coherencia y sentido a las acciones que configuran una práctica social. ... serían una suerte de código genético cultural que cada generación trasmite a la que le sigue" (López Novo, 1993: 316).

4. El último paso en esta reciente reacción contra el objetivismo clásico lo ofrece la etnometolodología, al menos en algunas de sus variantes: "nuestra preocupación en el "orden" es sólo y específicamente con este hecho visible y así "creado" para la acción práctica, a través de las práctica. El orden sólo existe en la medida en que es creído y, por lo tanto, creado por los propios actores que as í lo perciben (Lamo de Espinosa: 44).

5. Según López Novo, las instituciones poseen dos dimensiones: 1) el eje horizontal o conectivo se refiere a la coherencia interna de las instituciones y al tipo de encadenamientos y relaciones que mantienen con otras instituciones u órdenes institucionales. 2) Se refiere al modo en que las instituciones configuran la identidad de los actores y modelan sus posibilidades de acción. El viejo institucionalismo privilegiaba la dimensión horizontal, el nuevo tiene la posibilidad de mantener el equilibrio entre ambas dimensiones y respetar el requisito metodológico de la traducción de los argumentos macroinstitucionales a cadenas de microinteracciones (López Novo, 1993: 320).

\section{Referencias Bibliográficas}

1. Aguiar, Fernando (1993), “Confianza y racionalidad", en: Problemas de teoría social contemporánea, Lamo de Espinosa, Emilio y Rodríguez, Ibáñez, José (eds.), CIS, Madrid.

2. Barañano, Margarita (1992), Los fundamentos de la teoría social de Thorstein B. Veblen, "la revuelta" contra el homo oeconomicus de la "economía recibida". Tesis doctoral, Universidad Complutense de Madrid, Departamento de Estructura Social, Sociología III, Madrid.

3. Bauman, Zygmunt (1999b), En busca de la política. Fondo de Cultura Económica de Argentina, S.A., Argentina.

4. Berger, Peter y Luckmann, Thomas (1998), La construcción social de la realidad. Amorrortu editores, Argentina.

5. Chandler, Alfred J r. (1987), Strategy and Structure, chapters in the history of the industrial Enterprise". The M.I.T. Press, United States of American.

6. Chandler, Alfred Jr. (1988), La mano visible, la revolución en la dirección de la 
empresa norteamericana. Ministerio de Trabajo y Seguridad Social de España, Madrid.

7. Croizier, M. y Friedberg, E. (1990), El actor y el sistema. Alianza editorial, México.

8. Dombois, Rainer (1997), “Relaciones industriales y condiciones laborales", en: Weiss, Anita (editor), Modernización industrial: empresas y trabajadores. Universidad Nacional de Colombia, Departamento de Sociología, Bogotá.

9. Duplon John (comp.) (1985), EI Trabajo en el Siglo XX. Madrid, España, Ministerio de Seguridad Social.

10. Dunlop, John (1978), Sistema de relaciones industriales. Ediciones Península, Homo sociologicus, Barcelona.

11. Espina, Álvaro (1999), “La "guadiana” de la concertación neocorporativista en España: de la huelga general de 1998 a los acuerdos de 1997", en: Mígueles, F. y Prieto, c. Las relaciones de empleo en España, Madrid, Siglo XXI, Madrid.

12. Gil, Calvo, Enrique (1993), “La hipótesis del rol "egoísta”. Límites de la teoría de la elección racional", en: Problemas de teoría social contemporánea, Lamo de Espinosa, Emilia y Rodríguez, Ibáñez, José (edts.), CIS, Madrid.

13. Garrido, Medina, Luis y Gil, Calvo, Enrique (eds.) (1993), Estrategias familiares. Alianza Editorial, España.

14. Giner, Salvador, Lamo de Espinosa, Emilio y Torres, Cristobal (eds.) (1998), Diccionario de Sociología. Ciencias Sociales, Alianza Editorial, Madrid.

15. Hyman, Richard (1981), Relaciones industriales: una introducción marxista. H. Blume, Madrid.

16. Hyman, Richard y Ferner, Anthony (1994), New frontiers in European industrial relations, Blackwell Bussines, Osford, UK.

17. Kern, H. y Shumann, M. (1988), El Fin de la División del Trabajo. España, Ministerio de Seguridad Social.

18. Kerr Clark, Dunlop John, Harbison Frederick y Myers Charles (1963), EI industrialismo y el hombre industrial. Insora de la Universidad de Chile y 
Eubeda, Editorial de la Universidad de Buenos Aires, Argentina.

19. Kerr, Clark, Dunlop, John, Harbison, Frederick y Myers, Charles (1971), Post scriptum a "El industrialismo y el hombre industrial", en: Revista Internacional del trabajo, vol. 83, No. 6, Ginebra. pp. 589-614.

20. Kochan, Thomas \& Piores, Michael (1990), Proposal for comparative research on industrial relations and human resource policy and practice. Experts' meeting, OECD, Paris, May 1991.

21. Kochan, Thomas and Useem, Michael (edit) (1992), Transforming organizations. Oxford University Press, USA.

22. Kochan, Thomas, Katz C. Harriz y MacKersie, Robert (1993), La transformación de las relaciones laborales en los Estados Unidos. Ministerio de Trabajo y Seguridad Social, Madrid.

23. Kochan, Thomas \& Osterman, Paul (1994), The mutual gains enterprise, forging a winning partnership among labor, management, and government. Harvard Business Scholl Press, Boston, Massachusetts.

24. Kochan Thomas, Locke, Richard and Piore Michael (edit) (1995), Employment relations in a changing world Economy. MIT Press, Cambridge, Massachusetts, London, Ingland.

25. Kochan, Thomas, Lansbury, Russell D. y MacDuffie, John Paul (edit) (1997), After lean production, envolving employment practices in the world auto industry. ILR Press- and Imprint of Cornell University Press, I thaca and London.

26. Lamo de Espinosa, Emilio (1990), La sociedad reflexivas, sujeto y objeto del conocimiento sociológico. Siglo XXI, de España Editores, S.A., Centro de investigaciones sociológicas CIS, Madrid.

27. Lamo de Espinosa, Emilio (1993), “La interacción reflexiva”, en: Problemas de teoría social contemporánea. Edición a cargo de Emilio Lamo Espinosa y José Enrique Rodríguez I báñez, Cis, Centro de investigaciones sociológicas, Madrid.

28. Lamo de Espinosa, Emilio (1996), Sociedades de cultura, sociedades de ciencia, ensayos sobre la condición moderna. Ediciones Nobel, Madrid. 
29. ke, Richard; Kochan, Thomas y Piore, Michael (1995a) "Replanteamiento del estudio comparado de las relaciones laborales: enseñanzas de una investigación internacional" en Revista Internacional del Trabajo, Vol. 114, No. 2, Edit. OIT, pp.157-184, Ginebra.

30. López Novo, Joaquín P. (1993), “Neoinstitucionalismo económico y teoría sociológica", en: Problemas de teoría social contemporánea, CIS, Madrid.

31. Lucena, Héctor (1998), “El movimiento obrero petrolero, proceso de formación y desarrollo", 3 ed., José Agustín Catalá, editor, Caracas, Venezuela.

32. March, James y Olsen, Johan P. (1997), El redescubrimiento de las instituciones, la base organizativa de la política. Estudio introductorio de Rodolfo Vergara, Colegio de Ciencias Políticas y Administración Pública, A.C., Universidad Autónoma de Sinaloa y Fondo de Cultura Económica, México.

33. March, James y Olsen, Johan (1984), "The new institutionalism: organizational..." in: The American Political Science Review, 78, pp. 734-749.

34. North, D.C. (1990), "Institutions and their consequences for economic performance", en K.S. Cook y M. Levi (comp.), The limits of rationality, Chicago, Chicago University Press.

35. Offe, Claus (1990), Contradicciones del Estado de Bienestar. Alianza Editorial, Madrid.

36. Osterman (comp.) (1988), Los mercados de trabajo. Ministerio de Trabajo y Seguridad Social, Madrid.

37. Piore, Michel y Sabel, Charles (1990), La Segunda Ruptura Industrial. Versión española de María Esther Rabasco y Luis Toharia, Alianza Editorial, España.

38. Requeijo, Jaime (1984), "Presencia y vigencia del institucionalismo". Revista Información Comercial Española, No. 607, Marzo, pág. 77-88, España.

39. Ruysseveld, Joris Van, Huiskamp, Rien y Hoof, Jacques Van (1995), Comparative industial \& employment relations. SAGE Publications Ltd., London.

40. Ruysseveldt, Joris Van and Visser, Jelle (1996), Industrial relations in Europe, traditions and transititions. SAGE Publications Ltd., London, Open Universiteit, 
Herlen.

41. Sabel, Charles (1985), Trabajo y Política: la División del Trabajo en la I ndustria. España, Ministerio de Trabajo y Seguridad Social.

42. Vergara, Rodolfo (1993), “Decisiones, organizaciones y nuevo institucionalismo", en: Revista Perfiles Latinoamericanos, 3, pp. 119-144, M éxico.

43. Vergara, Rodolfo (1997), “El redescubrimiento de las instituciones: de la teoría organizacional a la ciencia política", en: Mach, James y Olsen, Johan, Redescubrimiento de las instituciones, la base de la organización de la política. Colegio Nacional de Ciencias Políticas y Administración Pública, A.C, Universidad Autónoma de Sinaloa y Fondo de Cultura Económica, México.

44. Villa, Paola (1986), La reestructuración de los mercados de trabajo, la siderurgia y la construcción en I talia. Ministerio de Trabajo y Seguridad Social, España.

45. Watson, Tony (1995), Trabajo y Sociedad, manual introductorio a la sociología del trabajo, industrial y de la empresa. Hacer Editorial, Barcelona, España. 